\title{
Protective Effects of Ocimum basilicum Against Atrophic Changes in Graafian Follicles in Cyclophosphamide Induced Ovarian Toxicity
}

${ }^{1}$ Saba Saleem, ${ }^{2}$ Muhammad Suhail, ${ }^{1}$ Saba Amjad, ${ }^{3}$ Faiza Irshad

${ }^{1}$ Department of Anatomy, UCMD, University of Lahore, Lahore

${ }^{2}$ Department of Anatomy, Shaikh Zayed Medical Complex, Lahore

${ }^{3}$ Department of Anatomy, M Islam Medical \& Dental College, Gujranwala

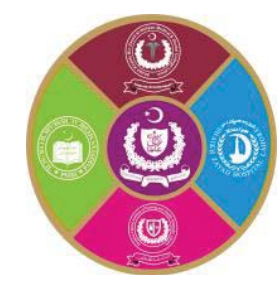

\section{ABSTRACT}

Introduction: Cyclophosphamide is one of the alkylating chemotherapeutic drug used in cancer patients that has antifertility effects on female gonads. Ocimum basilicum is a natural herb rich in polyphenols and is known to improve fertility. Aims \& Objectives: The study was designed to evaluate the role of natural herb, Ocimum basilicum extract, as a preventive agent against ovarian follicular toxicity induced by cyclophosphamide. Place and duration of study: This experimental study was performed in the Department of Anatomy, Shaikh Zayed Postgraduate Medical Institute, Lahore. The duration of study was 8 months. Material \& Methods: 45 female albino rats were divided equally in control group A, experimental group B and group $\mathrm{C}$ each contained 15 rats. Group A rats received single dose of $150 \mathrm{mg} / \mathrm{kg}$ normal saline intraperitoneally on $8^{\text {th }}$ day of experiment, while group B was given single intraperitoneal dose of $150 \mathrm{mg} / \mathrm{kg}$ cyclophosphamide at day 8 of experiment. Group $\mathrm{C}$ rats were pretreated with methanolic basil (Ocimum basilicum) seeds extract for 7 days followed by single intraperitoneal dose of $150 \mathrm{mg} / \mathrm{kg}$ cyclophosphamide at day 8 of experiment. All the rats were dissected 48 hours after the last dose. Results: Graafian follicles were atrophied showing atretic granulosa cells in group B when compared with control group A with p value $<0.001$. However, significant improvement in status of Graafian follicles was observed in group C, when compared with group B with $\mathrm{p}$ value $<0.025$. Conclusion: This study depicts that basil seeds extract can prevent the cellular toxicity in Graafian follicles caused by cyclophosphamide treatment. So the use of basil seeds during chemotherapy can significantly limit its toxic effects on Graafian follicles.

Key words: Cyclophosphamide, oxidative stress, follicular atrophy, basil.

\section{INTRODUCTION}

\section{$\mathrm{C}$} yclophosphamide is a commonly used effective anticancer alkaloid as well as an effective immunosuppressive drug. Cyclophosphamide gave the best desired result when tested against 33 tumors in comparison with 1000 other agents. ${ }^{1}$ It is a useful alkylating drug that belongs to group oxazophosphorine and was first introduced by Bourseaux, Arnold and Brock in 1958. ${ }^{2}$ This alkylating drug causes cytotoxicity by shifting its alkyl group to various constituents of tumor cells especially their DNA which causes cell death. Alkylation of guanine is common which results in abnormal pairing of guanine with thymine causing formation of abnormal DNA strands. ${ }^{3}$

Cyclophosphamide is being used to treat malignant breast carcinoma, Hodgkin's lymphoma and autoimmune disorders like systemic lupus erythematosus and glomerulonephritis. ${ }^{4,5,6}$ Cyclophosphamide, like other chemotherapeutic drugs, has adverse effects on different organ systems of body. Severity of adverse effects showed direct relation with dose of drug. Most common side effects are immunosuppression, nausea, vomiting, myelosuppression, weight loss and loss of appetite. ${ }^{7}$ It is known to cause increased susceptibility to infections, haemorrhagic cystitis, nausea, vomiting, hair loss and permanent infertility in humans even at therapeutic doses. ${ }^{8}$

Nowadays, increasing use of chemotherapeutic drugs for treatment of lupus nephritis and breast cancer in young females is causing premature menopause and secondary infertility due to post treatment ovarian failure. ${ }^{9,10}$ The mechanism of ovarian toxicity with cyclophosphamide involves decreased levels of antioxidant enzymes i.e. superoxide dismutase and catalase, resulting in excess of free radicals causing oxidative tissue damage. ${ }^{11}$ A study on female rats showed the dose dependent relationship between different doses of cyclophosphamide and antral follicular atresia. ${ }^{12}$ 
Ocimum basilicum (basil) plant belongs to the family Lamiacaea, species Ocimum basilicum and Genus Ocimum. ${ }^{13}$ Basil is called "King of Herbs" because of its wide usage and advantages. ${ }^{14}$ High content of phenolics in extract of various parts of this basil give it significant antioxidant potential in various in-vitro studies. ${ }^{15}$ When basil was used along with other medicinal herbs for treating oligospermia in males, it showed significant improvement in semen catalase levels and semen parameters proving that reduction in oxidative stress by increasing antioxidant enzymes in gonads can improve chances of fertility because free radicles are a big factor in infertility. ${ }^{16}$ An experiment on female rats also proved antioxidant potential of its methanolic extract given at dose of $1.5 \mathrm{~g} / \mathrm{kg}$ in combination with exposure to electromagnetic field (EMF) and results showed significant improvement in various histological parameters of ovaries including granulosa cell apoptosis, fibrosis and venous congestion, when compared with other group that received only EMF exposure. ${ }^{17}$

Cyclophosphamide is being frequently used in recent past years to treat malignancies. Major adverse effect of cyclophosphamide, when used in young females having CA breast, is secondary infertility due to its direct effects on primordial and growing follicles resulting in oxidative damage. ${ }^{18}$ It is obvious from past studies that natural antioxidants have protective effect when used in combination with cyclophosphamide. ${ }^{11}$ Present study is therefore designed to see the antioxidant potential of basil seeds extract against cyclophosphamide induced ovarian toxicity.

\section{MATERIAL AND METHODS}

This experimental study was performed in the Department of Anatomy, Shaikh Zayed Postgraduate Medical Institute, Lahore.

The sample size was estimated by using power and precision 3.0 software with 0.48 effect using and 2.28 as error SD. Based on this a total of 45 adult healthy female albino rats (3-4 months old), average female weight 190-240 gm were used in this study. All these animals were kept in cages in the animal house of the Department of Anatomy, Punjab PGMI, Lahore. The animals were allowed free access to food and water. A commercial brand of chick feed No. 1 was provided to rats, (Appendix-I). In every $5 \mathrm{~kg}$ of this feed, wheat flour $2.5 \mathrm{~kg}$, molasses $1 \mathrm{~kg}$, fish meal 100 grams and water was added. A 12:12 light: dark cycle was maintained. Temperature was maintained between $22-25^{\circ} \mathrm{C}$.
Basil seeds were extracted with methanol. Nonvolatile compounds were extracted by solvent extraction method. Weighted samples were taken in a flask and it was filled with solvent. These samples were regularly shaken for 48 hours with 3 hours interval. Then sample was filtered with filter paper and subjected to rotatory evaporation in order to remove solvent and then by air evaporation. Sample was stored in freezer to avoid loss of antioxidant compounds. ${ }^{19}$ Dosage solution for oral administration was prepared by dissolving extract in normal saline. ${ }^{20}$ Cyclophosphamide was purchased from pharmacy and dose of drug as $150 \mathrm{mg} / \mathrm{kg}$ body weight was calculated for each rat.

All rats were divided in three groups A, B and C. Each group contained 15 rats that were further named as A1-A15, B1-B15 and C1-C15 by lottery method. The rats were assigned that number and marked with permanent marker and placed in the specific group cage. The weight of each rat was carefully recorded, with the help of weighing machine, in a proforma.

The dose schedule was as follows:

Group A (Control): The rats of this group were not given any extract or toxic drug. These rats were provided with routine oral food daily and only given the single dose of normal saline $150 \mathrm{mg} / \mathrm{kg}$ body weight intraperitoneally on day 8 of experiment. ${ }^{20}$

Group B (Experimental): The rats of this group received routine oral food with other rats for 7 days followed by only a single dose of $150 \mathrm{mg} / \mathrm{kg}$ cyclophosphamide intraperitoneally at day 8 of experiment. ${ }^{11}$

Group C (Experimental): This experimental group received basil seed extract as dose of $1.5 \mathrm{~g} / \mathrm{kg} /$ day through gastric intubation for 7 days followed by single $150 \mathrm{mg} / \mathrm{kg}$ intraperitoneal dose of cyclophosphamide at day 8 of experiment. The extract was given on the same fixed time daily.

All the animals of group A, B and C were properly given analgesia at the end of experiment, 48 hours after giving the last toxic dose, by using $50 \mathrm{mg} / \mathrm{kg}$ ketamine followed by $50 \mathrm{mg} / \mathrm{kg}$ xylazine intraperitoneally. The animals were dissected and ovaries were removed. Hematoxylin and eosin stained slides were prepared for both right and left ovaries of each rat having 5 serial tissue sections in each slide.

Graafian follicles were observed for atretic changes in their follicular cells. The follicle was considered tertiary when oocyte was seen surrounded by corona radiata cells and there was only a single large cavity between compacted layers of granulosa cells and corona radiata cells. ${ }^{12}$ Granulosa cells were considered atretic when having pyknotic nuclei, 
irregular arrangement around oocyte and detachment from their basement membrane. ${ }^{11}$

\section{Statistical analysis:}

Qualitative data for Graafian follicles was analyzed by using frequency and percentage for each group. Then comparison was made among the groups by using Chi-square test. $\mathrm{P}$ value was considered significant when $<0.05$. Quantitative data was reported by using mean \pm SD. Comparison among the groups was made by using ANOVA.

\section{RESULTS}

Graafian follicles were observed normal in 13 rats (86.75) of control group A. Graafian follicles in only 2 rats of control group were atretic and deshaped. Atresia was seen in 12 rats $(80 \%)$ of group B and 6 rats $(40 \%)$ of group B, (Table-1).

\begin{tabular}{|c|c|c|c|c|c|c|}
\hline \multirow{2}{*}{ Group } & \multicolumn{6}{|c|}{ Graafian follicle } \\
\cline { 2 - 7 } & \multicolumn{2}{|c|}{ Normal } & \multicolumn{2}{c|}{ Atretic } & \multicolumn{2}{c|}{ Total } \\
\cline { 2 - 7 } & $\mathrm{N}$ & $\%$ & $\mathrm{~N}$ & $\%$ & $\mathrm{~N}$ & $\%$ \\
\hline Group A & 13 & 86.7 & 2 & 13.3 & 15 & 100.0 \\
\hline Group B & 3 & 20.0 & 12 & 80.0 & 15 & 100.0 \\
\hline Group C & 9 & 60.0 & 6 & 40.0 & 15 & 100.0 \\
\hline
\end{tabular}

Table-1: Status of Graafian follicles observed in control group $\mathrm{A}$, experimental groups $\mathrm{B}$ and $\mathrm{C}$.

Diameters of Graafian follicles showed significant decrease in diameters in toxic group $\mathrm{B}$, when compared with control group A with $\mathrm{p}$ value $<0.001$. There was improvement in diameters of follicles in experimental group $\mathrm{C}$ when compared with toxic group B with $\mathrm{p}$ value 0.005 , (Fig-1).

\begin{tabular}{|ll|}
\hline Groups A \& B & $<0.001^{* *}$ \\
Groups A \& C & 0.062 \\
Groups B \& C & $0.005^{*}$ \\
\hline
\end{tabular}

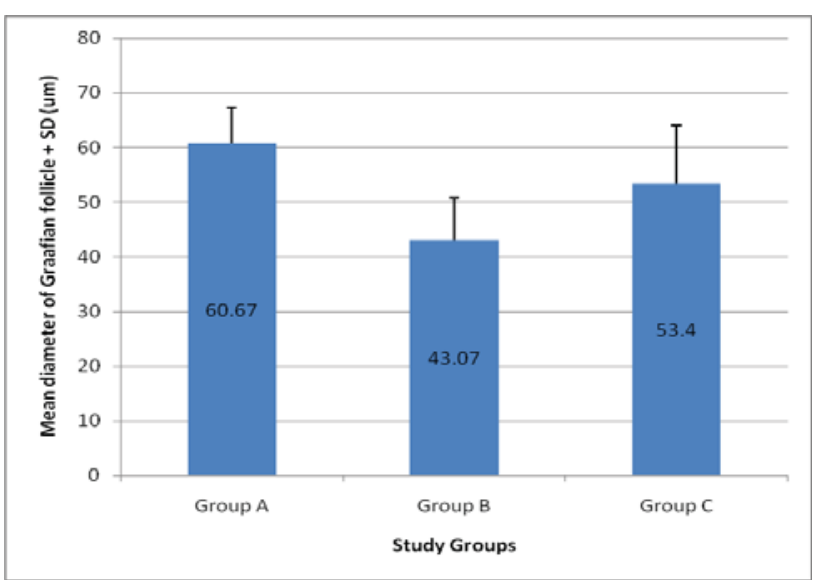

Fig-1: Diameter of Graafian follicle measured for control group A, experimental group B and C (error bar represents standard deviation). 


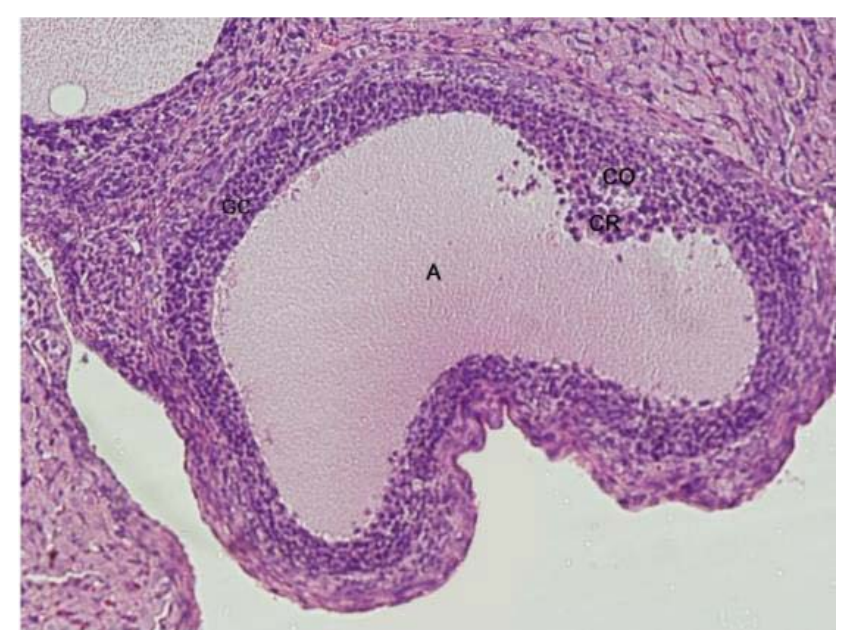

Fig-4: Photomicrograph of ovary of experimental group $\mathrm{C}$ having Graafian follicle showing follicular antrum (A), well arranged granulosa cell layer (GC), corona radiate (CR) and cumulous oophorus (CO), (H \& E, 20x).

When group wise comparison was made between control group A and experimental group B, the results were highly significant with $\mathrm{p}$-value $<0.001$. The difference observed between control group and experimental group $\mathrm{C}$ was not significant with $\mathrm{p}$ value 0.093. Comparison between experimental groups $\mathrm{B}$ and $\mathrm{C}$ showed significant difference with p-value 0.025, (Table-2).

\begin{tabular}{|c|c|c|}
\hline (I) Group & (J) Group & P-value \\
\hline \multirow{2}{*}{ Group A } & Group B & $<0.001^{* *}$ \\
\cline { 2 - 3 } & Group C & $0.093^{+}$ \\
\hline \multirow{2}{*}{ Group B } & Group C & $0.025^{*}$ \\
\hline
\end{tabular}

Table-2: Group wise comparison for status of Graafian follicles in control group A, experimental groups $\mathrm{B}$ and $\mathrm{C}$.

\section{DISCUSSION}

In the present study, cyclophosphamide affected Graafian follicles causing cell death and apoptosis of granulosa cells resulting atrophy of follicles. The results showed that there is significant improvement in status of Graafian follicles and its size in experimental group $\mathrm{C}$ receiving pretreatment with basil seeds extract, in comparison with toxic group $\mathrm{B}$ receiving only cyclophosphamide.

These changes observed in Graafian follicles in toxic group B are due to decreased levels of antioxidant enzymes and overproduction of free radicles caused by toxic effects of cyclophosphamide resulting in initiation of cell damage and apoptosis of damaged cells. ${ }^{11,21}$ Another important mechanism that explains the cell death and apoptosis of granulosa cells causing atrophy of
Graafian follicles, is the cytotoxic action of phosphoramide mustard, one of its active metabolic compound formed by liver. ${ }^{22}$ This phosphoramide mustard caused alkylation of guanine base of DNA and resulted in formation of abnormal DNA causing cell cycle arrest and apoptosis in rapidly dividing cells of gonads. $^{3}$

The significant improvement in status and size of Graafian follicles was observed in group C, given basil seed extract and cyclophosphamide, (Fig$1,2,3,4)$. This can be explained by the antioxidant and free radical scavenging property of seed extract of Ocimum basilicum that can be responsible for prevention of oxidative damage in gonads. ${ }^{23-28}$ The antioxidant mechanism of action of Ocimum basilicum has also been proved in the study performed by Khaki A. In this study Ocimum basilicum extract protected the rat tissue against oxidative damage induced by electromagnetic field. ${ }^{29}$

\section{CONCLUSION}

The results of the present study proved that basil seed extract can protect Graafian follicles when given as a preventive treatment along with cyclophosphamide by improving the atrophic changes in granulosa cells of mature follicles induced by cyclophosphamide. The results also suggest the clinical use of basil seeds extract for prevention of infertility induced by cyclophosphamide.

\section{REFERENCES}

1. Emadi A, Jones R.J., Brodsky RA. Cyclophosphamide and cancer: golden anniversary. Nature reviews Clinical oncology. 2009; 6 (11):638-647.

2. Chighizola C, Ong VH, Denton CP. Cyclophosphamide as disease-modifying therapy for scleroderma: pros and cons. International Journal of Clinical Rheumatology. 2011; 6(2):219-227.

3. Edward C. Alan C. Sartorelli. Cancer chemotherapy, In: Bertram G. Katzung, Susan B. Basic and Clinical Pharmacology $12^{\text {th }}$ edition. New York, USA: Mc Graw Hill Companies; 2012. p. 953.

4. Edward C. Alan C. Sartorelli. Cancer chemotherapy, In: Bertram G. Katzung, Susan B. Masters (eds.). Basic and Clinical Pharmacology $12^{\text {th }}$ edition. New York, USA: Mc Graw Hill Companies; 2012. p. 953. 
5. Hudson MM, Schwartz C, Constine LS. Treatment of pediatric Hodgkin lymphoma. In Pediatric Lymphomas 2007: 35-48.

6. Houssiau FA, Vasconcelos C, D'Cruz D, Sebastiani GD, Garrido ED, Danieli MG, Abramovicz D, Blockmans D, Mathieu A, Direskeneli H, Galeazzi M. Immunosuppressive therapy in lupus nephritis: the Euro-Lupus Nephritis Trial, a randomized trial of low-dose versus high-dose intravenous cyclophosphamide. Arthritis \& Rheumatism. 2002; 46(8):2121-31.

7. Zhong S, Huang M, Yang X, Liang L, Wang Y, Romkes $\mathrm{M}$ et al. Relationship of glutathione S-transferase genotypes with side-effects of pulsed cyclophosphamide therapy in patients with systemic lupus erythematosus. British journal of clinical pharmacology. 2006; 62(4): 457-72.

8. Teles KA, Medeiros-Souza P, Lima FA, Araújo BG, Lima RA. Cyclophosphamide administration routine in autoimmune rheumatic diseases: a review. Revista brasileira de reumatologia. 2017; 57(6):596-604.

9. Wetzels JF. Cyclophosphamide-induced gonadal toxicity: a treatment dilemma in patients with lupus nephritis. Netherlands Journal of Medicine. 2004; 62(10):347-52.

10. Meirow D, Nugent D. The effects of radiotherapy and chemotherapy on female reproduction. Human reproduction update. 2001; 7(6):535-43.

11. Yener NA, Sinanoglu O, Ilter E, Celik A, Sezgin G, Midi A et al. Effects of spirulina on cyclophosphamide-induced ovarian toxicity in rats: biochemical and histomorphometric evaluation of the ovary. Biochemistry research international. 2013; 764262.

12. Kamarzaman S, Shaban M, Abdul Rahman S. The prophylactic effect of Nigella sativa against cyclophosphamide in the ovarian follicles of matured adult mice: a preliminary study. J Anim Plant Sci. 2014 Jan 1; 24:81-85.

13. Stanojković-Sebić A, Dinić Z, Iličić R, Pivić R, Jošić D. Effect of indigenous Pseudomonas chlororaphis strains on morphological and main chemical growth parameters of basil (Ocimum basilicum L.). Ratarstvo I povrtarstvo. 2017; 54(2):42-7.

14. Michele Meyers. Basil: An Herb Society of America Guide. The Herb Society of America 9019 Kirtland Chardon Rd. Kirtland.2003.p.1-7.

15. Juliani HR, Simon JE. Antioxidant activity of basil. Trends in new crops and new uses. 2002;575
16. Alizadeh H, Khaki A, Farzadi L, Nouri M, Ahmadi-Asrbadr Y, Seyed-Ghiasi G et al. The therapeutic effects of a medicinal plant mixture in capsule form on catalase levels in the semen of men with oligospermia. Crescent Journal of Medical and Biological Sciences. 2015;2(1):1-4.

17. Khaki A, Khaki AA, Ezzatzadeh A, Hamidreza A. Effect of Ocimum basilicum on ovary tissue histopathology after exposure to electromagnetic fields (EMF) in rats. African Journal of Pharmacy and Pharmacology. 2013; 7(25): 1703-1706.

18. Amoura Z, Duhaut P, Sbai A, Costedoat N, Wechsler B, Piette JC. Risk of ovarian failure and fertility after intravenous cyclophosphamide. A study in 84 patients. The Journal of rheumatology. 2002; 29(12):2571-6.

19. AYDEMIR T, Becerik S. Phenolic content and antioxidant activity of different extracts from Ocimum basilicum, Apium graveolens and Lepidium sativum seeds. Journal of food biochemistry. 2011; 35(1):62-79.

20. Rasekh HR, Hosseinzadeh L, Mehri S, KamliNejad M, Aslani M, Tanbakoosazan F. Safety assessment of ocimum basilicum hydroalcoholic extract in wistar rats: acute and subchronic toxicity studies. Iranian journal of basic medical sciences. 2012; 15(1):645.

21. Devine PJ, Perreault SD, Luderer U. Roles of reactive oxygen species and antioxidants in ovarian toxicity. Biology of reproduction. 2012; 86(2):27, 1-10.

22. Chouhan RS, Ahmad B, Chauhan R, Shrivastava VK. Ameliorative role of ascorbic acid against hepatotoxicity induced by chemotherapeutic drug cyclophosphamide in male albino rat. International Journal of Biological \& Pharmaceutical Research. 2014; 5(11):830-42.

23. Kaurinovic B, Popovic M, Vlaisavljevic S, Trivic S. Antioxidant capacity of Ocimum basilicum L. and Origanum vulgare L. extracts. Molecules. 2011; 16(9):7401-14.

24. Gajendiran A, Thangaraman V, Thangamani S, Ravi D, Abraham J. Antimicrobial, antioxidant and anticancer screening of Ocimum basilicum seeds. Bulletin of Pharmaceutical Research. 2016; 6(3):114-9.

25. Fekri N, Khayami M, Heidari R, Jamee R. Chemical analysis of flaxseed, sweet basil, dragon head and quince seed mucilages. Research Journal of Biological Sciences. 2008; 3(2):166-70.

26. Stevanović ZD, Radanović D. Proceedings of the Seventh Conference on Medicinal and 
Aromatic Plants of Southeast European Countries, (Proceedings of the 7th CMAPSEEC). Institute for Medicinal Plant Research and Association for Medicinal and Aromatic Plants of Southeast European Countries (AMAPSEEC). Subotica, Serbia, 2012: 267-273.

27. Hussain AI, Anwar F, Sherazi ST, Przybylski R. Chemical composition, antioxidant and antimicrobial activities of basil (Ocimum basilicum) essential oils depends on seasonal variations. Food chemistry.2008;108(3):986-95.

28. Shirazi MT, Gholami H, Kavoosi G, Rowshan V, Tafsiry A. Chemical composition, antioxidant, antimicrobial and cytotoxic activities of $\mathrm{T}$ agetesminuta and Ocimum basilicum essential oils. Food science \& nutrition. 2014; 2(2):146-55.

29. Khaki A. Protective Effect of Ocimum basilicum on brain cells exposed to oxidative damage by electromagnetic field in rat: Ultrastructural study by transmission electron microscopy. Crescent Journal of Medical and Biological Sciences. 2016; 3(1):1-7.

\section{The Authors:}

Dr. Saba Saleem,

Assistant Professor

Department of Anatomy,

UCMD, University of Lahore.

Prof. Muhammad Suhail

Head, Department of Anatomy,

Shaikh Zayed Medical Complex, Lahore.

Dr. Saba Amjad,

Assistant Professor,

Department of Anatomy,

UCMD, University of Lahore.

Dr. Faiza Irshad,

Associate Professor,

Department of Anatomy,

M Islam Medical and Dental College, Gujranwala.

\section{Corresponding Author:}

Dr. Saba Saleem,

Assistant Professor,

Department of Anatomy,

UCMD, University of Lahore.

E-mail: saba_saleem786@hotmail.com 